\title{
Renegotiating Community Life: Arts, agency, inclusion and wellbeing
}

\author{
Martin Mulligan, Christopher Scanlon AND NiCKy WelCh
}

$\mathrm{T}$

The community arts sector in Australia has grown enormously in scale and diversity over the last thirty years (Mills 2006). While there is no consensus on how to define community arts as distinct from other forms of art practice, the term is being used widely to refer to art practices that encourage active participation by people who can be identified by their membership of designated communities rather than their skills and/or experience as artists (Mills 2006). The growth of community arts in Australia has been accompanied by a growing international trend which has seen community arts positioned as a community development tool. As a report commissioned by the RAND Corporation in the US (McCarthy et al. 2004) demonstrated, there has been a growing emphasis on an 'instrumental' role for the arts in achieving specific social outcomes, ranging from reducing incidents of crime to increasing school retention rates. At a broader level it has been argued (see, for 
example, Williams 1996; Richards 2006) that community-based arts projects can lead to tangible improvements in the health and wellbeing of local communities and this argument has been used to call for an increase in funding for community arts. Yet the evidence for the benefits of participating in community arts and cultural activities remains unconvincing and attempts to define the health and wellbeing benefits of the arts have borne little fruit (McQueenThomson \& Ziguras 2002; Cultural Ministers Council 2004).

Studies on the social benefits of community arts have reached an impasse for three main reasons. First, the questions being asked are often too narrow and the research methods too limited in range and scope. Second, much of the literature in the field relies on static understandings of community that pay little attention to the changing nature of local community life in the context of globalization. Third, and related to the first two factors, some of the conceptual tools being used to analyse the data, such as the notion of 'social capital' for example, tend to be reductive and are of only limited help in understanding the complexity of community.

This article is based on the outcomes of a four-year study, conducted across four diverse local communities in the Australian state of Victoria, on ways in which community-based arts and cultural projects can enhance community wellbeing. The research specifically aimed to avoid the weaknesses of earlier research on this topic by taking a broader view of what constitutes community-based art work and by using a carefully integrated combination of quantitative and qualitative research methods across the four case study communities.

This article seeks to address the question of social inclusion and it draws on the use of photonarrative techniques that help to reach socially excluded people. An article of this length could not do justice to all the research methods used in the study or to all the outcomes that are included in a 177-page research report (Mulligan et al. 2006). It does, however, aim to demonstrate the importance of moving beyond narrow links between arts initiatives and social outcomes to discuss some of the more intangible, diffuse, and sometimes unexpected outcomes. As a result of this emphasis, the broad study reached the conclusion that the open-ended nature of the arts can help to generate and sustain webs of meaning at a time when shared narratives and frameworks of meaning of community are being 
challenged by the disruptive effects of the intersecting social processes of 'globalization'.

Such social benefits cannot be understood in terms of quantifiable outcomes but rather in terms of the ways in which participation with arts-based projects can help individuals and groups of people to negotiate contemporary changes confronting the communities in which they live. In contrast to a focus on social capital, this article centres on notions of 'social narrative' and 'social inclusion'. Expressed in its simplest terms, our argument is that community arts can positively affect health and wellbeing because they can enable individuals and groups of people to develop narratives of action in response to social change.

Although the research used a wide range of methods ranging from community surveys to 'strategic conversations' with experienced community arts practitioners (Mulligan et al. 2006), this article relies primarily on the outcomes of the photonarrative research conducted with marginalized people living in the four communities. Details of the photonarrative technique used in the study will be provided later. However, to explain why this focus of attention produced some interesting and fresh insights, and to explain why the researchers used the photonarrative technique, we must begin by drawing some lessons from the methodological and conceptual weaknesses of earlier research in this field.

\section{Social and Cultural Dimensions in Health Policy}

In an effort to curb the increasing costs associated with health, governments around the world have pursued a diverse range of strategies aimed at promoting behavioural change, such as antismoking and healthy eating campaigns. Other approaches have sought to reach beyond the level of individual behavioural modification to a concern with the social and cultural contexts of health and wellbeing. Central to such concerns is the idea that health and wellbeing have social and cultural dimensions (as well as biological) and this has led to an emphasis on creating social and cultural environments that might produce better health outcomes.

Many of these social health strategies have drawn support from the booming literature on 'social capital', loosely defined as networks of trust, cooperation, reciprocity and mutual obligation, between individuals and groups. According to advocates of social capital, increasing such networks by encouraging individuals to 'participate' 
has a range of positive and desirable public policy outcomes, from increasing economic efficiency, improving academic performance, lowering crime rates and - the focus of this article - improving public health and wellbeing. As Robert Putnam, a leading proponent of social capital observes:

Of all the domains in which I have traced the consequences of social capital, in none is the importance of social connectedness so well established as in the case of health and wellbeing. (Putnam 2000, p. 326)

Putnam is not alone in his positive assessment of the impact of social connectedness on health and wellbeing. Reviewing the literature examining social connectedness and mortality rates, for example, Cohen $(2001$, p. 6) reports that the 'health risks of being isolated are comparable in magnitude to the risks associated with cigarette smoking, blood pressure, and obesity, and remain even after controlling these and other traditional risk factors'.

With such certain and apparently authoritative backing, policy makers and health bodies have pursued social connectedness as a tool for improving population health and wellbeing. In Australia, the Victorian Health Promotion Foundation, known as VicHealth - a funding partner in the research project on which this article is based has used social capital to inform and guide its approach to mental health and wellbeing. VicHealth has, more specifically, sought to harness the arts and cultural activities as a means of promoting social connectedness and social inclusion, funding community arts activities since its inception in 1987 (VicHealth 2002; 2006). At a broad, abstract level the evidence to support this kind of emphasis in health promotion policies seems robust. However, as mentioned above, the research on how it works in practice is less than convincing and has been hampered by both methodological and conceptual weaknesses.

First, many of the studies in this area are based on research that is only likely to be convincing to those within the field. A review of the literature on the links between arts and indicators of mental, social and physical health conducted by McQueen-Thomson and Ziguras (2002), found that much of the research has been based on selective case studies, anecdotal accounts, small sample sizes and subjective assessments of outcomes. Moreover, many of the studies examined 
by McQueen-Thomson and Ziguras were short-term in nature and, in some cases, were carried out by people who were too close to funding bodies to make what could be considered objective assessments (McQueen-Thomson \& Ziguras 2002). In short, much of the research on this topic has been narrowly conceived and selfreferential in nature, finding 'evidence' to support existing assumptions. A broader review of the literature on the 'social benefits' of the arts (McCarthy et al. 2004) reached very similar conclusions about research conducted in the US, and Paola Merli (2003) has made similar criticisms of the 'evidence' used by Francois Matarasso to support his influential argument for the social benefits of arts participation (Matarasso 1997).

Such critiques should not, however, lead to a condemnation of all the efforts made to date to employ the arts for social outcomes because the anecdotal evidence regarding the unique benefits derived from participation in arts-based projects is very strong (see Mulligan et al. 2006). Furthermore, we need to broaden our understanding of what constitutes 'evidence' because it comes in a wide variety of forms. Matarasso mounted a spirited defence of his work against Merli's critique (Matarasso 2003) in which he rightly pointed out that the demand for rigorous 'proof' of beneficial links fails to take into account the complexity of those connections. According to Matarasso, Merli's critique was also far too dismissive of the partial evidence that is available. What we need is more and diverse evidence rather than a sweeping rejection of the useful work done by people such as Matarasso.

The conceptual problem is that some researchers have been looking for linear relationships of causality when the relationships between inputs (arts and cultural projects) and (social) outcomes is much more indirect and diffuse than that. To overcome this problem, the research on which this article is based concentrated on how artsbased projects can be employed to create the conditions in which individuals and groups of people can renegotiate the terms of their involvement in their local communities without trying to predict the particular outcomes resulting from such increases in individual and group agency.

A second methodological and conceptual problem with much of the recent research on relationships between the arts and health and wellbeing is its heavy reliance on imprecise and problematic conceptual tools, such as the interrelated concepts of 'social capital' 
and 'social inclusion'. In their review of the literature on social capital and health promotion, for example, Hawe and Shiell (2000, p. 880) argue that this concept lacks theoretical precision, and is often used uncritically and in a circular way to refer to "all that is "good" within a community'. Social capital can thus be moulded to fit in with whatever indicators of social health and wellbeing are being used, rather than offering insight of itself.

Similarly, practical applications of social capital have been found wanting. A pacesetting study on the social impacts of the arts in Australia (Williams 1996) that relied heavily on the vague notion of social capital did not help arts practitioners or funding agencies to better understand the strengths and weaknesses of emerging community arts practices, as Williams herself acknowledged (1997). 'Social inclusion' has sometimes been seen as a policy prescription that follows on from social capital. This term gained credibility when it was adopted by the Blair government in the UK to replace notions such as 'social equity'.

In commenting on the UK experience, which included a Cabinetlevel Social Exclusion Unit to investigate barriers to inclusion, Ruth Lister (2000) claims that many people took advantage of this shift in terminology to blame the poor for their own plight and most of the policies aimed at overcoming exclusion were aimed at getting people into paid employment - often to join the 'working poor' - when the causes of exclusion are more wide-ranging than the lack of a steady income. However, she argued that the notion of exclusion can be more targeted and effective than broad terms such as 'poverty' or 'disadvantage'. Lister argued for the retention of social inclusion provided that the causes of exclusion are addressed at what she called 'material' and 'symbolic' levels (Lister 2000).

Other commentators (see, for example, Hinkson 1999, pp. 109110) have argued that policies of social inclusion may simply encourage greater participation in social structures that may actually entrench problems - such as poor health and poor academic achievement - for those at the bottom of social hierarchies. Such critics argue that inclusion may draw people into the 'global market' that is reconstituting the communities in which they live and that this can intensify feelings of insecurity and disempowerment. More specifically, critics such as Hawkes (2004) have warned against using the arts as a band-aid or a diversion to avoid the need for systemic 
change to address the causes of disadvantage. In his conference paper (2004), Hawkes went as far as saying that some of the 'best' art can be 'terrifying, disturbing and disorienting' as a form of social critique that does not aim to enhance 'wellbeing' within existing social structures.

However, social inclusion can also be used as a critique of social practices and structures that constantly recreate division and 'disadvantage'. In this study we have sought to critically retrieve the concept from its narrow and shallow uses, thus decoupling 'social inclusion' from the concept of 'social capital', with its bias towards quantitative or economic visions of social life (Fine 2001). This is not necessarily to reject 'social capital' completely, but to use it in a far more restricted and precise sense than is presently the case (Scanlon 2006). However, this study reached the conclusion that previous attempts to make sense of community arts practice by introducing the notion of social capital (see, for example, Williams 1996) have not been helpful to practitioners. By contrast, the concept of 'social inclusion' does make sense to such practitioners.

A third problem with the existing research on using the arts as a tool for community development is that it is often based on static and one-dimensional understandings of what constitutes communities in the contemporary world. A number of social theorists (see, for example, Young 1990; Hobsbawm 1994) have argued that the notion of 'community' is, at best, vague and ambiguous or, even worse, that it creates outdated and romanticized notions of social norms that are oppressive to those who do not fit such norms. As Hobsbawm (1994, p. 428) suggests: 'Never was the word "community" used more indiscriminately and emptily than in the decades when communities in the sociological sense became hard to find in real life'. More recently Walmsley $(2006$, p. 5) began a review on 'the nature of community' by saying that the word has been used so loosely for so long that it now has a 'high level of use but a low level of meaning'. Nevertheless, he argued that the term 'community' reflects aspirations for forms of social life that are gaining in their appeal and that we need to investigate some of the more constructive ways in which the term is being used to enhance social life.

Many of those who want to rescue the word community from its most narrow, romanticized or utilitarian uses turn back to the 
distinction made as long ago as 1887 by Ferdinand Tönnies ${ }^{1}$ between gemeinshaft communities that are relatively stable and feature established networks and relationships based on mutual obligation and gesellschaft communities in which people are far more mobile and concerned with individual self-interest (see, for example, Lowe 2000; Stehlik 2006; Walmsley 2006). While Tönnies was writing at a time when masses of people were moving out of established rural communities to seek work in the burgeoning cities as a result of the Industrial Revolution in Europe, his terminology has been used to argue that local communities can display a mixture of the two characteristics and that some gesellschaft communities can regain at least some of the characteristics of gemeinschaft communities (see Lowe 2000).

Given their enduring appeal, Tönnies' concepts of different forms of community should not be dismissed and there are still plenty of local rural communities in the world that display gemeinschaft characteristics. However, the changing nature of local communities in the intervening 130 years, and particularly its reconstitution through processes of globalization, heavily qualifies the usefulness of these now dated concepts. Part of the problem with discussing community within the context of globalization is that much of the literature on globalization has limited usefulness in understanding community. Indeed it is only relatively recently that some scholars have recognized the 'lure of the local' in connection with global change (see, for example, Featherstone 1996; Lippard 1997).

Paul James $(1996 ; 2006)$ has argued that accelerated globalization has not resulted in the replacement of old social formations with new ones but rather an increased layering of social life from local face-toface communities through to more abstracted and spatially extended communities (the nation and beyond). People belong simultaneously to 'communities' that operate at different levels of abstraction and instead of focusing on one or another aspect of this multilayered existence we need to examine how these levels interact.

In elaborating these criticisms of the methodological and conceptual weaknesses of existing research on the health and wellbeing benefits of arts participation, we must reach the conclusion that the impasse is unlikely to be broken by conducting further

\footnotetext{
${ }^{1} \mathrm{~A}$ book by Tönnies was published in German in 1887 under the title Gemeinschaft und Gesellschaft.
} 
research of a similar kind to what has already been undertaken. While study after study shows that there is some kind of connection between participation in community cultural events and projects and improved wellbeing, adequately explaining how that connection works is still to be accomplished. We must find ways to get beyond mechanistic accounts of the relationship between social interventions and their complex 'outcomes'.

\section{A FRESH APPROACH}

This article is based on the outcomes of a four-year study, conducted across four diverse Australian communities, on the contribution that community-based arts and cultural activities might be able to make to the wellbeing of local communities. The study was prompted by the aforementioned literature review conducted by McQueenThomson and Ziguras (2002), which highlighted the need for a new and broader approach to this field of research. Ironically, the broadening of the research focus led to a departure from some of the specific recommendations made by McQueen-Thomson and Ziguras. Rather than continuing the futile search for tight links between strategies aimed at strengthening local communities and specific health outcomes, the research tried to understand the distinctive role that participatory arts and community celebrations can play in helping diverse local communities cohere more successfully and to develop narratives of meaning that can stand the test of time in a changing world. Following James (1996; 2006), our research for this project is situated within a broader interest in what can make local communities more sustainable in the context of globalization.

\section{THE FOUR RESEARCH SITES}

Four research sites in the southern Australian mainland state of Victoria were chosen to provide focus and spread to the research. We were careful not to assume that the geography alone defined community, hence the use of the term 'research site', rather than 'community'. The research sites included some in which there has been a proud tradition of community art work and some where community arts are being introduced 'from above' in an attempt to enrich local life.

St Kilda is an established inner-urban suburb of Melbourne with a large migrant population, particularly European Jewish, and a high proportion of young upwardly-mobile people. Alongside these 
relatively wealthy residents exist a group with lower and fewer socioeconomic means, and a high number of residents of public housing and rooming houses and, indeed, homeless people. It has a rich tradition of using innovative community arts activities to foster inclusion and social connection.

In contrast, Hamilton is a rural community located in the southwest corner of Victoria. Prior to the arrival of European migrants in the 1840s, Hamilton was a flourishing area for the Indigenous people and it has continued to be a place of relative prosperity brought about primarily by sheep farming. Hamilton is known for its affluence and social and political conservatism, a reputation that has survived more recent rural recessions. Although Hamilton is not without a community arts scene, it has nothing like the extensive, targeted and ongoing community arts activities of St Kilda.

Just over 100 kilometres from Melbourne, the small town of Daylesford has become a popular destination for weekend visitors attracted by its natural mineral springs and historic guesthouses. Daylesford has a rich history of Swiss-Italian migrants who pioneered European settlement in the area during the gold rush in the 1850s and 60s. For a small rural town it has, like the inner urban St Kilda, a rich and varied cultural life, including the second largest gay and lesbian celebration in Australia after the world famous Sydney 'Gay and Lesbian Mardi Gras'.

Finally, the peri-urban Melbourne suburb Broadmeadows began in the 1950s as a hastily built public housing estate on the edge of Melbourne. An influx of migrants from non-English speaking countries dramatically changed the population mix in later years. Currently over thirty three per cent of the population comes from non-English speaking backgrounds with around fourteen per cent of residents coming from the Middle East (Australian Bureau of Statistics 2001). The area also includes a large number of singleparent families, many families on very low incomes, and a relatively high proportion of people unable to find employment (Australian Bureau of Statistics 2001). While the local council facilitates excellent community arts initiatives, it is on a far smaller scale than the diverse range offered in both St Kilda and Daylesford.

Across the four communities a wide range of events, projects and programmes were examined. These ranged from regular festivals to classes and other activities run by community-based organisations for 
targeted sectors of the community, and to one-off celebrations or creative initiatives that emerged more organically from within the communities concerned (see Mulligan et al. 2006 for more details on the activities examined). Unlike some earlier studies the research was not restricted to projects funded by government or semi-government agencies.

\section{METHODS}

Research was conducted in the four communities amongst both initiators and participants in community arts projects and community celebrations and a special effort was made to consult people who rarely, if ever, participate in such events. The specific methods used included two questionnaires $(n=800)$, thirty semi-structured interviews / conversations, the collation of fifteen local stories, and four sets of photonarrative inquiry. Following Ezzy (2002), the methods were chosen to reflect the aims of the project and to ensure that diverse forms of 'evidence' regarding the social benefits of arts participation could be considered.

Research participants were recruited through a variety of channels, using purposive sampling techniques. While deliberate in the sense that certain groups were identified as being relevant to the phenomena studied (Pope \& Mays 1995), the aim of purposive sampling is to generate difference. A number of strategies were used to generate a sample that would provide data to address the aims of the research. Community arts, community development and community health workers were all interviewed, as were participants in a range of community art projects and programmes. However, we also used methods that were aimed at finding out when and why people participate in community arts activities (surveys) and we also used the photonarrative technique to target people who might have good reason to feel socially isolated (such as people with 'special needs' and 'at-risk' youth).

An initial questionnaire was designed for a mail-out survey of 3000 residents in the four communities (with a response rate of around ten per cent for the urban communities and around twenty percent for the rural communities). This generated broad data about perceptions of local community life in a changing world (Mulligan et al. 2006, Chapter 4) and it prompted a more targeted survey of people attending community arts projects and events or significant community celebrations. Whereas the first survey revealed some 
barriers to participation in local community projects and events, the second survey sought to explore what attendees might have gained from their participation (Mulligan et al. 2006, Chapter 4). Lengthy interviews with community arts and community development practitioners across the four communities led to a detailed analysis of what constitutes 'good practice' within these overlapping fields in Australia (Mulligan \& Smith 2007 and Mulligan et al. 2006).

However, for the purpose of our discussion here on how people in local communities might use the arts to renegotiate the terms of their engagement in those communities, we will rely primarily on the outcomes of our use of photonarrative techniques to explore problematic experiences of social inclusion and community engagement. While the two surveys gave the researchers a broad view of the issues related to participation in community arts and practitioner interviews gave us a deeper understanding of effective practice, the photonarrative technique enabled us to target some social groupings whose participation in community life is often problematic. For example, we used the technique to explore the experience of community life for people living in rooming houses in the St Kilda area and we targeted young people and men suffering social isolation in the rural township of Daylesford. By focusing on such marginalized groups of people we were able to test some prevailing assumptions about the nature and benefit of social inclusion, and that is the focus of this particular article.

There are, of course, many research techniques that rely on the use of cameras to explore less conscious aspects of people's lived experiences (see Harper 1984; Wang \& Burris 1994, 1997; Wang \& Redwood-Jones 2001). We employed a 'photonarrative' technique that involved distributing cameras to participants recruited to the project and asking them to take photos that might express their sense of community. This was followed by semi-structured interviews with each of these research participants centring on the images they had taken. The researchers were then able to analyse the lengthy transcripts of these interviews. In each of the research sites, the photonarrative research was carried out with assistance from local organisations and groups, such as community health centres, neighbourhood bodies and local government officers. The process for recruiting participants was lengthy and in each case a fairly small percentage of initial participants completed the task and the 
subsequent interviews. The number of completions ranged from over twenty in the case of St Kilda to just two at Broadmeadows. Clearly, this is a narrow sampling and the technique would not stand on its own as an exploration of community life. However, it did produce some interesting and unexpected outcomes that would not have been picked up by the other research methods used (as outlined above).

Incorporating cameras as a research tool has been used in a number of contexts to examine health and wellbeing issues (see Wang \& Burris 1997; Booth \& Booth 2003; McIntyre 2003). However, as distinct from some other approaches that utilize photography as a research tool (see Wang \& Burris 1997), our photonarrative technique makes no claim of 'empowering' participants in the research.

The outcomes of our photonarrative research are complemented in the discussion below by some slightly surprising outcomes of our survey of people participating in a range of significant community celebrations and events.

\section{DISCUSSION OF RESEARCH FINDINGS}

In analysing participant transcripts across the four communities, three key propositions emerged:

- the communities are undergoing enormous changes in the present era of globalization in ways that directly confront issues of personal identity and a sense of narrative

- participation in community arts and celebrations can create individual and/or collective narratives of action within a local context

- reflective participation in community arts and celebrations can enhance choice in regard to the ways in which individuals and groups manage their engagement with local communities.

\section{GLOBALIZATION AND CONSTRUCTING NEW NARRATIVES}

We live at a time when shared narratives, and their frameworks of meaning, have been weakened and individual self-identity has become, in Ulrich Beck's terms, a 'do-it-yourself biography' (1992, p. 135). Less and less is prescribed by external agents and events and more and more has to be chosen and re-chosen, negotiated and renegotiated. While it would be difficult to sustain the thesis that the contemporary world is more fragmented than was the case in the past, the kinds of fragmentation now seem to cut deeper. There are 
fewer overarching structures and institutions through which individuals might negotiate forms of social inclusion.

While such institutions of the past could be stifling and oppressive, they also gave people a relatively secure sense of who they were and how they ought to live (see, for example, Brett \& Moran 2006, pp. 10-11, 15-47). Contemporary life is increasingly governed by what Richard Sennett (1998) calls the maxim of 'no long term'. In such circumstances, individuals are increasingly forced to use their own resources to develop a coherent sense of self and identity, to develop narratives of self that help to create a degree of stability in the face of change. For some, the new 'freedom of expression' can be liberating while for others it can be disorienting, offering little more than evanescent and contingent reference points.

The photonarrative interviews gave some insight into such changes at the level of community life, of the abiding bonds of community being overtaken, restructured, and reconstituted by forces of more mobile, fleeting forms of association celebrated by the boosters of neo-liberal globalization. For example, an interviewee who lived in an apartment complex on busy St Kilda Road spoke of the fast-changing nature of his community. He mentioned that he knew the people who had lived in the building for a long time because he recognized their cars in the car park. The arrival and departure of other residents of the complex was registered by signs advertising furniture and appliances being posted on the apartment noticeboard as residents prepared to vacate the building. There was a sense here of community in a constant process of flux, created, dissolving and re-created. Perhaps not surprisingly, this interviewee reported that he did not feel that he was part of his community and that his parents had a stronger experience of community than he did.

There were other signs of community being overlaid by processes and activities, which went beyond, and worked to reframe, the local bonds of community. A common theme amongst the interviewees was that face-to-face community was under threat from a variety of processes variously described as centralization or corporatization. Such concerns typically emerged when people were invited to reflect on whether community life was weakening, strengthening or staying pretty much the same. An interviewee in St Kilda, for instance, said her community was becoming 'more corporate' as large corporations displaced smaller shops, producing a more anonymous street life 
which was seen as having a negative impact on the kinds of community who were likely to settle and live in St Kilda:

Unless the eclectic-ness still attracts those who have those qualities - if we can maintain that, then people will still want to live here and express that. But if it gets too Becton [a large property developer], too development, too Jeans West [a clothing chain store], then you'll get an average kind of mindset.

While specific corporations were mentioned, these seemed intended more as specific examples of a more general way of life which was experienced as hostile to stable, settled forms of community, where individuals could develop a coherent identity and narrative. One respondent spoke about changes to the local library claiming that it was:

... one of those meeting places that keeps people connected. The local librarian knows all the town gossip because people come in and blab. Old people come in and bring her cakes, probably more for a yak than the books, so it is another one of those institutions which they keep wanting to streamline and corporatize and privatize and fuck up. If they left them alone they would be fine. They are important.

Another interviewee, from Daylesford, mentioned his frustration with the local service station which seemed to be representative of the impersonality of large corporate chains, in opposition to the community that he had known.

I hate our Shell service station with a passion. Our local service station may employ a few workers, but the workers don't work for the community. I've been in there many times, [and] because I'm not a very rich person ... they treat us with contempt. As soon as I hang my bowser up, she'll see me coming and grab her computer and leave me hanging around until she's good and ready to serve me.

This concern with the impact of corporations is not focused on particular corporations but rather a perception that corporations in 
general represent a whole way of life which was seen as being impersonal and hostile to the 'natural' rhythms of community life. One interviewee illustrated the general theme, arguing that community was weakening because of the economic changes and the rise of corporations. The weakening of community, he said, had 'to do with having a job':

This thing at the moment of forcing people into work who are on pensions and on welfare. I'm all for that except, exactly what jobs are these people going to do? Where are the jobs? What are they going to do? Is it going to earn them an adequate wage or is it going to give them pride? Is it going to feed into their wellbeing and self-esteem? You get me started. It's to do with democracy, it's being supplanted by 'corpocracy' which is really the whole world being run by corporations ... Corporations and stock markets are driving marginal people out of a meaningful life.

In contrast to this picture of globalization, he offered what he called "the "cliché of the tea-lady". She had a pride - those sorts of jobs just don't exist anymore'.

\begin{abstract}
ARTS AND THE CONSTRUCTION OF NARRATIVES OF ACTION
The reference to the tea lady highlights the personal consequences of the changing nature of community within conditions of globalization. It summons up a loss of identity. As local communities have been buffeted and reconstituted by processes of globalization, the sources of individual identity seem more precarious and the way forward less clear. Within this changed context, the arts can play a role in providing a sense of narrative and purpose, and so facilitate a sense of agency, offering people the means of piecing together the fragments of life and a coherent sense of self.

Meryl, a female festival attendee commented that she had been involved with numerous other community arts events over a fifteenyear period. She noted 'I have gained friends, confidence and community links. [These are] VERY important to who I am today'. Clearly, Meryl's involvement in community arts had been an important source of her identity. Yet it must be noted that this was over a fifteen-year period of being centrally involved. This suggests
\end{abstract}


that short-term participation in community arts may not be a short cut or a quick fix to questions about managing identity. It requires considerable investment of time and energy.

This provides some support to the concern expressed by many community arts practitioners who maintain that funding often only allows for short-term projects that do not encourage the more beneficial longer-term involvement. To 'get something' from the community, respondents reported having to put something in, or, as in Meryl's case, many hours over a long period of time. Rather than offering an escape hatch, arts participation may offer a means of managing uncertainty, of reflexively building and re-building a sense of community and identity.

Perhaps more striking still was a participant in the photonarrative process who lived in a rooming house in St Kilda. He used art - in this case creative writing - to give a sense of narrative and structure to his life. The participant lived in a rooming house because he had had problems with drugs and alcohol over the years. His community was primarily others in the rooming house, who, he said, were dealing with 'drug problems and depressions'. 'The only problem with these sorts of communities', he continued, 'is that there are lots of people with their own problems. So it's not easy to live in environments like this'. Asked if the community was valuable to him, he answered:

No, not at all. Not this community at all. You need to
stay away from this sort of environment, otherwise
things just snowball. You get people drinking, and
next minute you are too. That's how it all starts.

This man used his writing as a means to construct an identity outside of alcoholism and drug use. He was a keen runner and regularly wrote one-page stories about his life that he thought about while running. The walls of his modest room were decorated with two heart-shaped sculptures made out of found objects. He explained that one was for running and the other was for writing, both of which had to be done properly and for the right reasons. As he explained, the hearts are 'a reminder for me that there are two things I need to do from the heart. If I didn't do that I would get all confused': 
It's important for me to do my one-page story every day. Just a one one-page story. I tread a very fine line with what I do. It's very important for me to do these things, and to do things properly as well. Otherwise there's no sense in doing it if I am not doing it properly.

This man was encouraged to take up writing by the existence of a Roomers Magazine initiated by community development workers employed by the local Port Phillip City Council. The magazine is distributed through local bookshops and news agencies and numerous writers contributing to the magazine have talked about their work at the high profile Melbourne Writers Festival and other literary festivals in Victoria. The fact that the magazine had published some of his stories gave this man a sense of validity and it was enough for him to know that his stories might be of interest to other, unknown, people. Writing became a daily practice that helped him deal with a difficult, even dangerous, local environment.

Another photonarrative participant, this time from Daylesford, provided a similarly stark example of the role of arts and community in affording some sense of identity and narrative. This man had been dealing with depression after a road accident. He had begun attending a local men's group called the 'men's shed', which was initiated by a community health worker with a strong interest in the arts who noticed that many men in this rural community rued the fact there seemed to be fewer opportunities to make and fix things with their own hands. So the 'men's shed' was set up to give them a chance to participate in manual tasks ranging from mechanical repairs to artistic practices. The 'men's shed' project stretches the prevailing understanding of what constitutes community art but it clearly gives participants new opportunities to be creative and productive. When this participant was asked what he got from his participation in the men's shed, he said:

Well it gets me out of bed. If it wasn't for the men's shed, I don't think I would be here today. It gives me the will to get out of bed. It involves my kids and my whole family. The men are now a part of my family, knocking on the door. 
Although the focus of the men's shed was on manual work, this man said that he had gradually become involved with the lives of other men who came to the shed and started to play an organising and co-ordination role. After recovering from a serious road accident, attending the shed had become a large part of his recovery process and it helped him adjust to a new sense of self.

\section{EXERCISING CHOICE IN FORMS OF ENGAGEMENT}

In making these comments about links between art, narrative and agency, we do not suggest that clear 'outcomes' in terms of 'community engagement' are automatic or unproblematic. Indeed, increased agency might lead to a more critical engagement with local communities, as Jon Hawkes has suggested (2004). For some of those we interviewed for our research, such as the man living in the St Kilda rooming house, artistic practices gave them an opportunity to better manage their forms of engagement rather than surrender to an assimilation in fairly toxic social environments. The rooming house writer was happy to share his stories but only when he could maintain a degree of distance:

I use my writing to help people. I give it to them and walk away. That way I don't take any of this shit on. I'm not a counsellor, and I don't want to be a counsellor. I am trying to teach people that they can live a normal life.

This 'inclusion-at-a-distance' made possible a mediated relationship with his community, enabling a form of participation in community life that was characterized simultaneously by both inclusion and exclusion. To the extent that arts participation can increase agency, this does not automatically lead to the creation of more bonded communities. Indeed, as we have seen, art can be used to create some distance. At the same time, it needs to be remembered that the rooming houses of St Kilda provide some kind of home within a vibrant neighbourhood for people who face rather bleak alternatives. Sustainability of rooming house communities might be better measured in terms of an absence of conflict and violence rather than in terms of social bonding. Sadly, the gentrification of St Kilda is leading to the closure of many of the rooming houses and a new form of social exclusion for the former residents. 
However, the desire for a mediated engagement with local communities was not confined to the residents of rooming houses. There were other photonarrative participants who suggested that tight-knit communities might not improve their own health and wellbeing. One person said that he needed to feel that he could opt in and out of his local communities: 'I'm not by nature a club person. I'd love to be a club person, I'd love to be a team person but it's not in my nature'.

Some people, it seems, eschew an intense engagement with other people in favour of a kind of 'cool civility'. When a photonarrative participant from Daylesford was asked if he thought it possible that community engagement might sometimes undermine individual wellbeing, he replied:

Sure. When the community is a rigid hierarchy, or where there is a lack of tolerance to varying forms of behaviour ... all those things, if you don't fit the mould then you are in trouble. My father's family comes from a tiny town in the Mallee [district] on the South Australian border. Gossip in those sorts of towns can be vicious.

Such responses suggest a need for a more nuanced understanding of what social inclusion looks like. Too often, simplistic notions of what an inclusive community should look like underpin the way this concept is advocated in health promotion literature. Our research suggests it is more important to focus on agency than on an uncritical conception of social inclusion.

Even when people do make the effort to participate in community arts activities or community celebrations they may not feel more 'included' as a result. One respondent to our survey of such participants highlighted a 'lack of inclusiveness' in his feedback about the event - a community flower show that is linked to a major festival in Daylesford - and added that 'the energy was closed and cliquey [sic], not embracive'. Yet another participant in the same event wrote, 'we only just arrived and are already excited about being here - the music, the colour, the sense of community, happy people being themselves and enjoying life!' A third, female, participant was even more enthusiastic in writing: 'The Kingfisher festival [held annually in Melbourne] is a standout every year [with 
a] community atmosphere unlike other festivals; I attend approximately ten to fifteen [festivals] per year'. Within the one event, participants can feel variously included and excluded and this gives weight to the views of experienced community arts practitioners that it is better to have a diversity of activities and programmes rather than expect too much of one project, no matter how 'successful' it might have seemed (Mulligan et al. 2006, chapter 10).

\section{CONCLUSION}

This article presents just some of the findings of a broad study on ways in which participatory arts and community celebrations can make a distinctive contribution to the health and wellbeing of people and their local communities (Mulligan et al. 2006). Even though the study used a range of quantitative and qualitative research methods across four distinct and diverse local communities, it had only limited success in reaching people who are not already engaged in some way with their local communities. However, the use of a photonarrative technique did enable us to reach an understanding of some of the complexities of contemporary local community life that has eluded other researchers interested in community wellbeing. This has generated new insights about how arts participation can help people renegotiate the terms of their engagement with their local communities.

The research has shifted the focus from a narrow search for the specific social 'benefits' of arts-based interventions in community life to a focus on processes that might give socially excluded people increased agency in a confusing and changing world. The insights gained suggest the need for a more nuanced understanding of the interlocking processes of social inclusion and exclusion in communities that are being constantly reconstituted through the local manifestations of broader, global processes. Globalization continues to undermine forms of community that generated a relatively secure sense of identity and belonging and the onus has shifted to individuals to do that work for themselves. As Richard Sennett has suggested (2006, pp. 183-188) people are trying to make their individual experiences cohere by creating a sense of 'narrative movement' about their lives and this is where arts participation can play a major role. Our research suggests that arts participation can help people develop new individual and group narratives that can 
increase their agency in managing their engagements with the communities in which they live. Participation in community arts and celebrations can stimulate greater reflection about self and society, leading to the creation of narratives of action that can apply locally. However, the outcomes of increased agency are diverse and difficult to predict and it is essential to avoid simplistic, static and onedimensional conceptions of 'community', 'social inclusion' and 'wellbeing'.

Earlier research on community wellbeing has been hampered by the careless use of conceptual tools, such as 'social capital' and 'social inclusion', which can mask the complexities of contemporary life. It is precisely because arts participation offers an open-ended approach to the exploration of lived experience that it can help people in their ongoing search for identity in a changing world. However, this makes it very difficult to predict the outcomes of that participation and the social benefits of arts participation can only be described in broad, flexible and non-instrumental terms (Mulligan \& Smith 2007).

The complex relationship between arts, agency and inclusion may be frustrating for people charged with the responsibility of turning experience into social policy or for ensuring that funding for projects aimed at community strengthening is well spent. They need to be reassured, however, that the evidence is mounting, in all its diverse forms, that arts participation has a distinctive and timely role to play in the contemporary world.

\section{REFERENCES}

Australian Bureau of Statistics 2001, 2001 Census Data, viewed 18 September 2006, http://www.abs.gov.au/.

Beck, U 1992, Risk society: Towards a new modernity, Sage, London.

Booth, T \& Booth, W 2003, 'In the frame: Photovoice and mothers with learning difficulties', Disability and Society, vol. 18 no. 4, pp. 431-442.

Brett, J \& Moran, A 2006, Ordinary peoples' politics: Australians talk about politics, life and the future of their country, Pluto, North Melbourne.

Cohen, S 2001, 'Social relationships and health: Berkman and Syme (1979)', Advances in Mind-Body Medicine, vol. 17, p. 6.

Cultural Ministers Council 2004, Social impacts of participation in the arts: Stage two report, evidence, issues and recommendations, Department of

Communications, Technology and the Arts, Canberra. 
Ezzy, D 2002, Qualitative analysis: Practice and innovation, Allen \& Unwin, Crows Nest, NSW.

Featherstone, M 1996, 'Localism, globalism and cultural identity', in R Wilson \& W Dissanayake (eds), Local/global: Cultural production and the transnational imaginary, Duke University Press, Durham, NC.

Fine, B 2001, Social capital versus social theory: Political economy and social science at the turn of the millennium, Routledge, London.

Harper, D 1984, 'Meaning and work: A study in photo elicitation', International Journal of Visual Sociology, vol. 2, no. 1, pp. 20-43.

Hawe, P \& Shiell, A 2000, 'Social capital and health promotion: A review', Social Science and Medicine, vol. 51, pp. 871-85.

Hawkes, J 2004, 'The fourth pillar revisited: Key questions about cultural sustainability: "Let them eat culture, or here comes another bandwagon", paper presented at the Fourth Pillar Conference, Melbourne Town Hall, November 2004, Cultural Development Network, Melbourne.

Hinkson, J 1999, 'Third way politics and social theory: Anthony Giddens' critique of globalisation', Arena Journal, vol. 13, pp. 109-110.

Hobsbawm, E 1994, The age of extremes: The short twentieth century, 1914-1991, Michael Joseph, London.

Jackson, M \& Herranz J 2002, Culture counts in communities: A framework for measurement, The Urban Institute, Washington.

James, P 1996, Nation formation: Towards a theory of abstract communities, Sage, London.

James, P 2006, Globalism, nationalism, tribalism: Bringing theory back in, Sage, London.

Lippard, L 1997, The lure of the local: Senses of place in a multicultural society, The New Press, New York.

Lister, R 2000, 'Strategies for social inclusion: Promoting social cohesion or social justice?', in P Askonas \& A Steward (eds), Social inclusion, possibilities and tensions, Macmillan, London.

Lowe, S 2000, 'Creating community: Art for community development', Journal of Contemporary Ethnography, vol. 29, no. 3, pp. 357-386.

Matarasso, F 1997, Use or ornament? The social impact of participation in the arts, Comedia, London.

Matarasso, F 2003, 'Smoke and mirrors: A response to Paola Merli's "Evaluation of the social impact of participation in arts Activities"', International Journal of Cultural Studies, vol. 9, no. 3, pp. 337-346. 
McCarthy, KF, Ondaatje, EH, Zakaras, L \& Brooks, A 2004, Gifts of the muse: Reframing the debate about the benefits of the arts, The RAND Corporation, Santa Monica, US.

McIntyre, A 2003, 'Through the eyes of women: Photovoice and participatory research as tools for re-imagining place', Gender, Place, and Culture, vol. 10, no. 1, pp. 47-66.

McQueen-Thomson, D \& Ziguras, C 2002, Promoting mental health and wellbeing through community and cultural development: A review of literature focussing on community arts practice, VicHealth \& The Globalism Institute (RMIT University), Melbourne.

Merli, P 2003, 'Evaluating the social impact of participation in arts activities: A critical review of Francois Matarasso's “Use or ornament?"', International Journal of Cultural Policy, vol. 8, no. 1 pp. 107-118.

Mills, D 2006, 'Cultural development and the arts in everyday life', discussion paper prepared for the Australia Council's Scoping Study Reference Group, Australia Council for the Arts, Strawberry Hills.

Mulligan, M, Humphery, K, James, P, Scanlon, C, Smith, P \& Welch, N 2006, Creating community: celebrations, arts and wellbeing within and across local communities, VicHealth and The Globalism Institute (RMIT University), Melbourne.

Mulligan, M \& Smith, P 2007, 'Stepping out of the shadows of neglect: Towards an understanding of socially applied community art in Australia', International Journal of the Arts in Society, vol. 1, issue 4, pp. 43-52.

Pope, C \& Mays, N 1995, 'Qualitative research: Reaching the parts other methods cannot reach: An introduction to qualitative methods in health and health services research', BMJ, vol. 311, pp. 42-45.

Putnam, RD 2000, Bowling alone: The collapse and revival of American community, Simon \& Schuster, New York.

Richards, M 2006, Growing the arts reap the harvest: Queensland's Arts Councils and how the arts build stronger communities, Post Pressed, Brisbane,

Queensland.

Scanlon, C 2006, 'The problem with social capital' in J de Lange \& S Battiston (eds), Community engagement in a multicultural society: Smokescreens and mirrors?, City of Darebin, Preston, pp. 52-57.

Sennett, R 1998, The corrosion of character: The personal consequences of work in the new capitalism, WW Norton, New York.

Sennett, R 2006, The culture of new capitalism, Yale University Press, New Haven, US. 
Social Exclusion Unit 2001, 'Preventing social exclusion', a report by the Social Exclusion Unit March 2001, Cabinet Office, London, 10, viewed 30 November 2001, http:/ / www.cabinetoffice.gov.uk/seu/2001/pse/pse.pdf.

Stehlik, D 2006, 'Community as palimpsest: The example of Perth', Dialogue, vol. 25, no. 1, pp. 41-49.

VicHealth 2002, 'Creative connections: Promoting mental health and wellbeing through community arts participation', viewed 31 May 2006, http: / / www.vichealth.vic.gov.au/assets / contentFiles / CreativeConnections \%20text.pdf.

VicHealth 2006, 'Community arts and participation scheme', viewed 31 May 2006, http:/ / www.vichealth.vic.gov.au/Content.aspx?topicID=119.

Walmsley, J 2006, 'Putting community in place', Dialogue, vol. 25, no. 1, pp. 5-12.

Wang, C \& Burris, MA 1994, 'Empowerment through photo novella: Portraits of participation', Health Education Quarterly, vol. 21, no. 2, pp. 171186.

Wang, C \& Burris, MA 1997, 'Photovoice: Concept, methodology and use for participatory needs assessment', Health Education and Behavior, vol. 24, no. 3, pp. 369-387.

Wang, C \& Redwood-Jones, YA 2001, 'Photovoice ethics: Perspectives from Flint Photovoice', Health Education E Behavior, vol. 28, no. 5, pp. 560-572.

Williams, D 1996, Creating social capital: A study of the long-term benefits from community-based arts funding, Community Arts Network of South Australia, Adelaide.

Williams, D 1997, How the arts measure up: Australian research into the social impact of arts programs, Comedia, London.

Young, IM 1990, Justice and the politics of difference, Princeton University Press, New Jersey. 